\title{
A method of expert evaluation and selection of innovative projects in the agri-business
}

\author{
Tatiana Marinchenko* \\ Russian Research Institute of Information and Feasibility Study on Engineering Support of Agribusi- \\ ness, Federal State Budgetary Scientific Institution (Rosinformagrotekh FSBSI), Department for in- \\ formation an analytical support of the agribusiness economic development, Pravdinsky Township, \\ Moscow Region, 141261, Russian Federation
}

\begin{abstract}
A component of innovation activities is the selection of innovation projects and the innovation assessment system underlying it. The problem of taking into account the features associated with the heterogeneity of innovative projects in agriculture, complexity of measurement of quality indicators and taking into account effects from social and environmental goals has not been methodically solved yet. It has led to the need to find an affordable method for the assessment of innovative projects that would be able to consider these problems. The method developed will allow selecting an innovative project from the non-homogeneous group. At the same time, various differences associated with the areas of projects, regional characteristics, scales, ultimate effects, and other parameters are levelled out. The method is a flexible tool that allows you to take into account a different number of criteria and set individual weighting depending on the tasks being solved.
\end{abstract}

\section{Introduction}

To ensure the competitiveness of the agribusiness in the global market, it is necessary to strengthen the innovative component. Agriculture turns into a high-tech industry, the production efficiency of which caused by introduction of new developments and technical means into production. The foundation of innovation activity is the support of the states of innovation activity, an active scientific and technical policy of the constituent entities of the Russian Federation and manufacturers, this support is then focused on facilitating the implementation of advanced technologies of a breakthrough nature. The infrastructure created in the country allows us to carry out the whole cycle of work, from the idea stage through to the commercialization, to test and demonstrate new developments, to perform training events, conferences, round tables: a whole range of events that allow us to disseminate the experience of best practices $[1,2]$. Scientific and technological progress in the agribusiness allows achieving high innovation activity by means of successive modernization of production, increasing its efficiency, ensuring the environment protection and successfully resolving issues of social development of the rural areas. This implies management at the state or regional level of the selection and support of the most promising innovative projects that

*Corresponding author: 9419428@mail.ru 
give the best economic and social effect. Project financing is becoming more widespread in the world and the Russian Federation [3, 4].

A function of any innovation project is improving the level of comfort of human living conditions, therefore, the mission of innovation projects and, thereafter, social consequences are key criteria estimating any project $[4,5]$. Therefore, there is a need to develop a comprehensive analysis of potential non-economic results of the project implementation: the assessment of social, environmental and other regionally significant effects. The social goals of the project should prevail in the formation of the state innovation policy, and the results of its implementation should be:

Qualitatively new standard of living as a result of an increase in the productivity and efficiency of social production and improvement in the living environment

Qualitatively new level of resource saving, labour productivity growth, achievement of high product competitiveness, improving the degree of processing of raw materials and involvement in the production turnover of waste production

Overcoming the technical backlog of the country.

However, many manifestations of the social effect are difficult or impossible to measure, while being limited only to their qualitative description. As a rule, the greater the social achievement, the more difficult it is to give it an integral quantitative assessment. Assessment of social effects is a difficult methodological aspect of determining the effectiveness of an innovative project. The most used methods for estimating innovative projects generally rely on quantitative analysis and consider of project implementation parameters. Moreover, the development of simple and flexible analysis methods for evaluating the potentiality of innovative projects allowing for the effects connected with their implementation is an important task [4].

Domestic and foreign authors dedicate directly or indirectly a significant number of their work to various aspects of tackling the issues of the agribusiness innovation activities. The works of Andreev P A, Bautin V M, Buklagin D S, Golubev A V, Demishkevich G M, Kozlov V V, Koshelev V M, Y F Lachuga, V I Nechaev, I S Sandu, I G Ushachev, V F Fedorenko, A L Eidis, G O Mensh, S Mathe, A Koutsouris, F Hermans, Bo Feng, B Poteralska, A Mazurkiewicz and some others are devoted to the study of the processes of the transfer and commercialization of innovation, formation of innovation systems, innovative policy development in the agricultural sector [6-18]. Mazurkiewicz A and Poteralska B presented the definition and classifications of barriers in the field of innovation activity. As opposed to the literature background, the authors propose their own classification of technology transfer barriers including the technical, organizational-economic, and system barriers [18].

The aim of the study is to develop a method for a comprehensive assessment of the noneconomic results of the implementation of an innovative project, such as social, environmental and other regionally significant effects. The proposed assessment method should be flexible enough to be able to change the number of criteria, introduce any new criteria atypical for economic assessment, and convert indicators of the estimated effects of different qualitative characteristics into quantitative ones. At the same time, the method should allow comparing projects from any branches of agriculture and projects of different scales while bringing quantitative characteristics to a single dimension of indicators.

\section{Methodology}

In the process of developing a method for evaluating innovative projects, the author of the article used methods of monographic, comparative and systemic analysis, synthesis, functional modeling and idealization. The information base of the study was scientific publications on the research subject by Russian and foreign scientists, recommendations for as- 
sessing projects used in world practice and in Russia. The method is based on the model of Content Group, an American consulting company, in which each criterion is scored as an expert assessment. Despite the fact that the project can receive the highest scores for individual parameters, it is important to have a comprehensive description of the project for the entire set of factors.

In order to to analyse the project in question and according to the Investment Projects Effectiveness Evaluation Guidelines (No. VK 477, dated 06.21.1999 in Russia based on the recommendations of UNIDO), a decision has been made to use the net present value (NPV), internal rate of return (IRR), profitability indexes, and discounted payback period (DPP). It is advisable to use these indicators to assess the project feasibility. However, the recommendations of UNIDO as a method are not acceptable when assessing innovative projects, since they do not consider the specifics and social effects of the innovative projects to be implemented, in particular, they do not consider the level of project innovativeness, social effects, etc. $[3,9]$. In order to reflect the social effects using the expert method, we have formulated the scores of their qualitative characteristics. For example, to assess the level of environmental impact of an innovation project, an expert responds to the question: 'How does the innovation project to be considered affect the environment in the region?' At the same time, the following responds were formulated and evaluated: 'Significantly improves'; 'Slightly improves'; 'Does not affect'; 'Affects negatively, but does not exceed the permissible limits'; 'The issue of environmental impact has not been worked out.' Qualitative assessments for other social indicators, which do not obscure single-level quantitative characteristics, are similarly formulated and scored.

Regarding criteria that include quantitative indicators, but are wide-scattered in their values (for example, net present value, payback period, budget efficiency, etc.), the following expert assessment procedure has been presented: the values of the criteria indicators are arranged sequentially in descending order; the entire range of values is taken as $100 \%$; the gradation increment is set to $20 \%$; the boundaries for each group of the entire series of values are calculated. In this case, the increment can be set to any value, e.g. to 5\%,10\% and so on, which depends on the number of projects compared.

This method allows you to compare and distribute the values with a big difference in physical terms in the groups to which the assigned scores correspond [17].

\section{Results and discussion}

With the emergence of the problem of selecting innovative projects in order to choose the best one for implementation or investment, the main provisions of the process of their examination have been developed. As a subject of research, an innovative project appears to experts as an investment project with the necessary justification for economic feasibility, scope and scheduling of CAPEX considering the focus on the implementation of the research results and the market demand for the final innovative product (goods). The initiators of the examination of innovative projects are usually investors and enterprises selecting projects for themselves.

There is no single methodology for evaluating innovative projects in Russia. The score and expert method of assessment is today the main in resolving the issues of financing and supporting scientific and technical developments. It is most advisable to use multi-criteria ratings. This is an ordered system in the form of a list of qualities of any objects expressed by quantitative indicators. The rating method means that initially acceptable values of each criterion must be determined. Full compliance with or excess of these values is rated by the highest score, deviations are rated by lower scores [6].

An analysis of the existing examination practice shows that today there is no agreed view on the criteria for evaluating innovative products. Industry guidelines have been de- 
veloped, for example, in construction, road construction, and scientific institutions have many methods for assessing educational innovations.

The main parameter for the selection of projects is the comparison of economic efficiency, that is to say, the ratio between the results of implementation and their costs. Regarding innovative projects, so-called strategic criteria are important, which are poorly formalized at the time of project selection, but which can significantly affect the future activities of the company [17]. Along with financial security and economic efficiency, an important role is played by fundamental novelty of innovation; patent purity; license protection; competitiveness, etc. Thus, in practice, multifactor models are widely used, in which qualitative characteristics and expert assessments are used apart from the economic and mathematical methods and quantitative parameters.

Guidelines for evaluating projects and selecting them for financing, the UNIDO methodology and other domestic and foreign projects for evaluating the effectiveness of projects offer many methods used for this purpose. All methods for evaluating the project feasibility are divided into two groups based on accounting and discounted estimates [2, 5-6]. Evaluation indicators based on static calculation methods allow using in the calculation of accounting data on innovative project investment costs and resulting revenue without their discounting over time. Indicators based on the use of static calculation methods are usually used in order to assess the small short-term real innovative project feasibility [17]. Performance evaluations based on discount calculation methods provide for discounting of investment costs and income for individual intervals of the project implementation period. Discounting the value is the process of bringing the future value of money to its present value by removing from their future amount the corresponding amount of interest called the discount.

Poteralska B presented examples of attempts undertaken by scholars and practitioners to combine the foresight methodology with other tools aimed at supporting the decisionmaking processes, then describes a system combining the foresight methodology, technology assessment, and intellectual capital measurement. The system is aimed at generating research projects of the future, characterized by a high innovativeness level and a significant commercial potential, to be executed at R\&D organizations and at enterprises, for which a necessary potential is available $[19,20]$.

The guidelines for the evaluation of investment projects and their selection for financing (No. VK477, June 21, 1999) establish the following key performance indicators for an investment project: commercial effectiveness taking into account the financial consequences of the project for its direct participants; budgetary efficiency reflecting the financial consequences of the project implementation for the federal, regional and local budgets and national-economic efficiency (including production and social) taking into account the costs and results associated with the implementation of the project that go beyond the direct financial interests of its participants [9].

The objective of the study was to develop an assessment method that would allow mathematically processing all expert assessments (conclusions), including the quantitative and qualitative effects of the innovative project implementation, while these assessment criteria will consider the achievement of many objectives, such as social, economic, environmental, etc., for better simulation of the cumulative effect. The heterogeneity of estimates determines the use of a score and expert method for the selection of innovative projects.

To solve this problem, it was proposed to select innovative projects using a list of criteria; the project is reviewed to comply with each of the established criteria and the project is evaluated for each criterion.

It is proposed to conduct an examination based on the following three groups of indicators: 
The first group is indicators of innovation. Currently, there are no strict criteria for 'novelty', a different interpretation of innovation is possible. The following indicators describing the project innovation were identified from an analysis of the scientific literature in this area:

- Level of innovation of the solutions to be proposed in a project (the availability of world or domestic peers and the degree of their prevalence)

- The total potential of an innovative project as the cumulative level of capacities arising in the process of implementing an innovative project, for example, research, testing, production, technological and others, in terms of impact on the activities of an enterprise, an industry, a region or a country.

- Availability of advantages over similar projects already implemented or being implemented and prospects for further R\&D, experimental technological developments, as well as industrial production

- Replication of an innovation project as the reproducibility of the implementation of an innovation project in other regions with similar climatic conditions.

The second group is economic indicators. To justify the effectiveness of innovative projects in accordance with the guidelines for evaluating the effectiveness of investment projects, it is advisable to apply the following indicators: net present value, budget efficiency of the use of allocated financial resources (a planned amount of taxes due to pay to budgets of all levels) and payback period (a planned payback period for costs of testing and implementation of the project). Therefore, they were taken as criteria characterizing economic efficiency [17].

The third group has included the following indicators that characterize the project implementer:

- $\quad$ Social efficiency, number of jobs created, e.g.:

- Impact of an innovation project on the region environment (improvement or deterioration of the environment)

- Availability of a positive production and financial reputation of the project implementer

- $\quad$ Experience in implementing an innovation or investment project

- $\quad$ Positive experience of production activities in the area, in which the innovative project has been implementing for at least 3 years.

Given the objectives of the project, the contribution of the groups of criteria to the final total value can be adjusted by introducing the coefficients $\mathrm{K}$.

The weighted averages of the innovation project are calculated as follows:

$$
K_{f}=\sum K_{1} \times a_{1}+\sum K_{2} \times a_{2}+\sum K_{3} \times a_{3},
$$

where:

$K_{f}$ is a final score of the innovation project the total amount of the innovation project, $\sum K_{1}$ is a sum of the arithmetic mean points of the first group of indicators, $a_{1}$ is a coefficient of the first group,

$\sum K_{2}$ is a sum of the arithmetic mean points of the second group of indicators, $a_{2}$ is a coefficient of the second group,

$\sum K_{3}$ is a sum of the arithmetic mean points of the third group, $a_{3}$ is a coefficient of the third group.

Once the weighted averages for innovation projects have been calculated, ranked lists are generated, in which innovative projects are arranged in descending order of their final scores. 
The score and expert method of assessment is today the main in deciding the issues of financing and supporting scientific and technical developments. The method allows assessing projects, which are different in the area of implementation (for example, in animal husbandry and crop production) and therefore difficult to compare without bringing to common indicators, in scores from a fixed range, e.g. from 10 to 50, based on qualitative characterization and quantitative values of performance. The final assessment for each criterion is obtained by calculating the arithmetic mean of the results of all expert evaluations. Depending on the range of tasks to be solved at the regional or enterprise level, the required number of groups of criteria can be laid down; their weight can be changed through coefficients based on the priority of the tasks to be solved and the number of criteria in the groups, because the more criteria in the group itself, the greater the contribution the group makes in total final score.

The developed methodology is unique because it allows solving economic and social issues in the framework of the implementation of regional measures to support innovative activity and can be used in decision making when selecting projects for grants

\section{Conclusion}

Intensive technological update is the most important condition for the success of innovative socially oriented development and the success of the country in global competition. In addition, innovations become the leading agribusiness economic growth factor that determines the national competitiveness, which would result in the agribusiness transition to Sustainable Development with a significant strengthening of Russia's position in the world food markets.

Such a strategy involves the selection of the most effective projects for implementation, which involves a multi-criteria assessment.

The use of scores according to criteria that are wide-scattered in indicators (rubles, percentages, years, places of work) allows converting them into relative indicators (scores) regardless of what region and what the spread of indicator values is and to bring their comparability status.

Thus, it is possible to compare innovative projects that have significant differences, different in scale, area of implementation, in regions that are different by initial conditions.

The developed method of evaluation and selection of innovative projects allows you to make a certain rating list, where the projects are located in the descending order of the cumulative effect.

\section{References}

1. I.G. Ushachev, et. al Formation of innovation system of AIC: mechanism of transfer of innovations (Moscow: Scientific consultant, 2019)

2. V.F. Fedorenko, T.E. Marinchenko, V.N. Kuzmin, Organizational and Economic Mechanism of Innovation Transfer in Agro-industrial Complex (Moscow: Rosinformagrotekh, 2016)

3. T.E. Marinchenko, Machinery and equipment for rural area, 1, 40-46 (2019)

4. A.V. Petrikov, Agribusiness: Economics, Management, 9, 4-11 (2018)

5. A.P. Korolkova, V.N. Kuzmin, T.E. Marinchenko, A.V. Goryacheva, Support and Stimulation of Demand for Innovative Products and Technologies in the Agricultural Sector (Moscow: Rosinformagrotekh, 2019)

6. L. Byzov, Rating Methodology, available at: https://www.proza.ru/2011/09/18/163 
7. G.S. Prokopyev, D.A. Chepik, L.Kh. Botasheva, Agricultural Economics of Russia, 2, 73-79 (2015)

8. I.S. Sandu, V.I. Nechaev, N.E. Ryzhenkova, Economics, labour, management in agriculture, 3(60), 3-8 (2020)

9. G.I. Khokhlova, Y.A. Yushina, Improvement of the mechanism of management of investment projects, Proceedings of Int. Scientific Conf. Information Society: Health, Economics and Law (Irkutsk, March 13-14, 2019)

10. A.V. Golubev, Bulletin of the V.P. Goryachkin Moscow State Agroengineering University, 6 (94), 46-52 (2019), https://elibrary.ru/item.asp?id=41565006

11. I.S. Sandu, N.E. Ryzhenkova, Scientific review: theory and practice, 4, 6-16 (2017)

12. A. Koutsouris, E. Zarokosta, Journal of Rural Studies, 73, 176-185 (2020)

13. F. Hermans, M. Stuiver, P. Beers, K. Kok, Agric. Syst 115, 117-128 (2013)

14. A. Koutsouris, Agriscience to Agribusiness. Innovation, Technology, and Knowledge Management, 337-359 (2018)

15. S. Mathe et al. Typology of Innovation Support Services (2016) https://agrispin.eu/wpcontent/uploads/2016/10/Report_Typology.pdf

16. Bo Feng, Jian Ma, Zhi-Ping Fan, Expert Systems with Applications 38(5), 5532-5543 (2011)

17. T.E. Marinchenko, V.N. Kuzmin, Machinery and equipment for rural area 2, 27-30 (2015)

18. A. Mazurkiewicz, B, Poteralska, Procedia Engineering 182, 457-465 (2017)

19. B. Poteralska, Procedia Engineering 182, 587-593 (2017), available at: https://doi.org/10.1016/j.proeng.2017.03.160

20. I.G. Ushachev et al Methodological approaches to the development of innovation and investment in the agricultural sector (Moscow: Scientific consultant, 2016) 